\title{
EFFECT OF LIQUID NITROGEN STORAGE TIME ON THE SURVIVAL AND REGENERATION OF SOMATIC EMBRYOS OF COCOA
}

\author{
A.K. QUAINOO \\ Department of Agronomy, University for Development Studies, Tamale, Ghana
}

(Received 18 May; 2009; accepted 9 June, 2009)

\begin{abstract}
Investigations were undertaken on the effect of liquid nitrogen (LN) storage time on survival and regeneration of somatic embryos of cocoa (Theobroma cacao l.). Somatic embryos from different cocoa genotypes (AMAZ 32, AMAZ 10-1, AMAZ 12, SIAL 93, and IMC 14) at $15.45 \%$ moisture content were cryopreserved in LN for one h, four and eight weeks. Somatic embryos of the genotypes emerged from the alginate beads at different periods 4 to 12 weeks post-cryopreservation. Individual genotypes subjected to low temperature storage time did not show significant differences in post-cryopreservation survival, although different genotypes responded differently with AMAZ 12 and IMC 14 recording the highest and lowest mean survival rates of 58\% and 35\%, respectively. Plantlets originating from five genotypes had been weaned and developed normally comparable to non-cryopreserved somatic embryo-derived plantlets in the glasshouse. The effects of low temperature storage time on survival and genetic stability of somatic embryos using genotypes from the same parental and distinct lines may contribute to long-term storage of cocoa germplasm.
\end{abstract}

Key Words: Cryopreservation, genotypes, Theobroma cacao

\section{RÉSUMÉ}

Une enquêtes relative à l'effet du temps de stockage de l'azote liquide (LN) sur la survie et la régénération des embryons somatiques de cacao (Theobroma cacao l.) avait été menées. Les embryons somatiques de différents génotypes du cacao (AMAZ 3-2, AMAZ 10-1, AMAZ 12, SIAL 93 et IMC 14) d'une tenneur en humidité de $15,45 \%$ avaient été preservés dans LN pour une heure, quatre semaines et huit semaines. Embryons somatiques des génotypes émergés de perles d’alginate à différentes périodes de 4 à 12 semaines en post cryoconservation. Les génotypes individuels soumis à la basse température au temps de stockage n’ont pas démontré des différences significatives après la cryoconservation, bien que différents génotypes avaient réagi différemment. Les génotypes AMAZ 12 et IMC 14 avaient enregistré des taux moyens de survie de l'embryon somatique, respectivement 58 $\%$ et $35 \%$. Les plantules issue de cinq génotypes avaient été sevrées et développées dans une serre par voie normale en comparativement à l'embryon somatique des plantules non cryoconservées. Les effets du temps de conservation à basse température sur la survie et la stabilité génétique des embryons somatiques en utilisant de génotypes issue de meme lignées parentales et de lignée parentales distinctes peuvent contribuer au stockage à long terme de matériel génétique du cacao.

Mots Clés: Cryoconservation, génotypes,Theobroma cacao

\section{INTRODUCTION}

Cocoa seeds are the source of cocoa powder and butter, which are important ingredients in chocolate and confectionery products ( $\mathrm{Li}$ et al.,
1998). Mature cocoa seeds have relatively high moisture content when harvested and this makes them unsuitable for prolonged storage (Chin and Pritchard, 1988). The hygroscopic nature of the seeds further worsens the storage prospects of 
the commodity. The recalcitrant nature of cocoa seeds poses serious problems to germplasm storage as it is intolerant to desiccation and freezing (Chandel et al., 1995).

For many crops, cryopreservation is being applied to overcome the limitations encountered by traditional germplasm conservation strategies in the field, seed and in vitro culture collections (Helliot et al., 2003). Currently, cryopreservation of plant tissues is the only viable option for the long-term storage of germplasm from species which produce recalcitrant seeds (Lynch, 1999).

Cryopreservation is the preservation of viable cells, tissues and organ in liquid nitrogen at $-196^{\circ} \mathrm{C}$ (Engelmann, 1991; Benson, 1999) and can be stored for indefinite periods without genetic erosion (Golmirzaie et al., 1999). This conserves plant genetic resources which can not be maintained using conventional preservation methods (Hargreaves et al., 1997; Sakai, 2004). This technique circumvents the loss of totipotency in plant systems and eliminates or reduces genetic variation frequently associated with extended culture of suspensions at physiological normal temperatures (Towill, 2005).

Cryopreservation of cocoa using zygotic embryos, embryonic axes, callus and somatic embryos as explants has been demonstrated. Pence (1991) designed a cryopreservation protocol for immature zygotic embryos of cocoa which resulted in genetically heterogeneous seeds. Florin et al. (2002) also designed a cryopreservation protocol for embryogenic callus of cocoa which were prone to somaclonal variation (Hao and Deng, 2002). Fang et al. (2004) established a cocoa-specific cryopreservation protocol for a few hours in which embryo survival was monitored under a series of encapsulation, pre-culture and dehydration regimes.

The possibility of monitoring cocoa somatic embryo survival under long (few weeks to several months) instead of short (few hours) cryopreservation procedure using encapsulation dehydration technique would be of great value for the long term preservation of cocoa. This study highlights the effects of low temperature storage time in liquid nitrogen (LN) on the emergence and survival of the somatic embryos of different cocoa genotypes.

\section{MATERIALS AND METHODS}

Experimental materials. Five cocoa genotypes (AMAZ 3-2, AMAZ 10-1, AMAZ 12, IMC 14 and SIAL 93) were the sources for secondary somatic embryo production. Somatic embryos were initiated from floral explants collected at the University of Reading Intermediate Cocoa Quarantine Unit, following the protocol of Li et al. (1998) and Maximova et al. (2002). Secondary somatic embryos were randomly harvested from the cultures and used in all trials. They were maintained inside $9 \mathrm{~cm}$ petri-dishes containing $25 \mathrm{ml}$ embryo development (ED) medium comprising DKW basal salts, $100 \mathrm{mg} \mathrm{l}^{-1}$ myoinositol, $2 \mathrm{mg} \mathrm{l}^{-1}$ thiamine- $\mathrm{HCl}, 1 \mathrm{mg} \mathrm{l}^{-1}$ nicotinic acid, $2 \mathrm{mg} \mathrm{l}^{-1}$ glycine, $30 \mathrm{~g} \mathrm{l}^{-1}$ sucrose, $1 \mathrm{~g} \mathrm{l}^{-1}$ glucose, and $2 \mathrm{~g} \mathrm{l}^{-1}$ Phytagel, pH 5.7 (Li et al., 1998). Early-cotyledonary stage embryos of the genotypes were used throughout the experiments.

Cryopreservation procedure. The cryopreservation procedure of Fang et al. (2004), based on optimal somatic embryo survival of cocoa (plating encapsulated somatic embryos on ED medium enriched with $0.75 \mathrm{M}$ sucrose for seven days and dehydration on $30 \mathrm{~g}$ of silica gel for $4 \mathrm{~h}$ ) was used. Somatic embryos (4-5 mm) were isolated from callus tissues and suspended for $30 \mathrm{~min}$. in calcium-free liquid ED medium containing $3 \%(\mathrm{w} / \mathrm{v})$ sodium alginate (from Macrocystic pyrifera, $\%$ viscosity, SIGMA) in a beaker. Pipette tips (diameter $6 \mathrm{~mm}$ ) were used to drop each encapsulated somatic embryo into liquid ED medium containing $100 \mathrm{mM}$ $\mathrm{CaCl}_{2} \cdot 2 \mathrm{H}_{2} \mathrm{O}$, in a beaker. After $30 \mathrm{~min}$. polymerisation, calcium alginate beads were rinsed three times with sterile water for 5 seconds each and blotted on sterile filter paper to remove surface moisture.

Ten batches of encapsulated somatic embryo per plate were used throughout the experiment. Encapsulated somatic embryos were plated on ED medium enriched with $0.75 \mathrm{M}$ sucrose for seven days before dehydration. The dehydration of the encapsulated somatic embryos was carried out inside $9 \mathrm{~cm}$ petri-dishes where the somatic embryos were supported on sterile filter paper 
placed on top of $30 \mathrm{~g}$ silica gel (pre-dried in oven at $60^{\circ} \mathrm{C}$ over night) sealed with nesco film for four h. Dried encapsulated somatic embryos (10) were transferred into $1.8 \mathrm{ml}$ cryo-tubes and stored in $\mathrm{LN}$ for $1 \mathrm{~h}, 4$ weeks or 8 weeks. The cryo-tubes containing the somatic embryos were thawed in a warm water bath at $35^{\circ} \mathrm{C}$ for $5 \mathrm{~min}$.

The embryos were removed from the cryotubes dried on sterilised filter paper in petri-dishes for one $h$ and plated on ED medium. Sub-culture of the plates took place every 14 days with the pre-culture, dehydration and recovery conducted in the dark at $25^{\circ} \mathrm{C}$. The mean time of emergence of somatic embryos of the cocoa genotypes from the alginate beads after low temperature treatment was assessed.

A completely randomised design was used with three replicates of ten embryos repeated three times per treatment. The embryos were assessed for survival, which is defined here as the embryo remaining green and emerging from the alginate beads. Encapsulated somatic embryos reaching the cotyledonary stage of development (when cotyledons are fully opened) were selected and converted into plantlets. Conversion was considered achieved when the development of primary roots and first true leaves were observed. All the cultures were kept for a minimum of four months before being designated as nonsurviving. For statistical analyses, the data was subjected to analysis of variance using Genstat for Windows $7^{\text {th }}$ edition.

Plant regeneration. The conversion of somatic embryos to plantlets was conducted under $16 \mathrm{~h}$ photoperiod (90 $\mu \mathrm{mol} \mathrm{m"2} \mathrm{s}^{\prime 1}$ irradiance) at $22^{\circ} \mathrm{C}$. Surviving somatic embryos were placed in $250 \mathrm{ml}$ glass jars containing $40 \mathrm{ml}$ primary embryo conversion (PEC) medium which comprised of DKW basal salts, $100 \mathrm{~m} \mathrm{~g} \mathrm{l}^{-1}$ myo-inositol, $2 \mathrm{mg}$ $\mathrm{l}^{-1}$ thiamine- $\mathrm{HCl}, 1 \mathrm{~m} \mathrm{~g} \mathrm{l}^{-1}$ nicotinic acid, $2 \mathrm{mg} \mathrm{l}^{-1}$ glycine, $0.3 \mathrm{~g} \mathrm{l}^{-1} \mathrm{KNO} 3,0.435 \mathrm{mg} \mathrm{l}^{-1}$ arginine, $0.187 \mathrm{mg} \mathrm{l}^{-1}$ glycine, $0.328 \mathrm{mg} \mathrm{l}^{-1}$ leucine, $0.456 \mathrm{mg}$ $\mathrm{l}^{-1}$ lysine, $0.51 \mathrm{mg} \mathrm{l}^{-1}$ tryptophane, $10 \mathrm{~g} \mathrm{l}^{-1}$ sucrose, $20 \mathrm{~g} \mathrm{l}^{-1}$ glucose, and $1.75 \mathrm{~g} \mathrm{l}^{-1}$ Phytagel, pH 5.8 (Young et al., 2000). The PEC medium was renewed every 20 days until the appearance of plants with true leaves and roots.
Acclimatisation of encapsulated plantlets. Healthy plantlets containing two or more true leaves were weaned in the glasshouse. The plantlets were carefully removed from the culture vessels with forceps and washed in warm water to remove the culture medium. The plantlets were then placed individually in $10.2 \mathrm{~cm}$ diameter plastic pots containing mixture of 3:1 SHL seed sowing compost (Sinclair, UK) and vermiculite watered until the compost was saturated. The potted plantlets were placed in propagators under shade and the vent gradually opened one week after culture. After one month, the successfully weaned plantlets were fed with Sangral liquid fertiliser (1:1:1 NPK, Sinclair, UK) once every month. Plantlets with two or more true leaves and healthy roots were weaned in the glasshouse. The number of plantlets successfully weaned (four months after conversion into plantlets) was recorded.

\section{RESULTS}

Somatic embryogenesis of cocoa genotypes. Data on secondary embryogenesis for the five experimental genotypes are shown in Table 1. Cocoa genotypes responded differently in terms of embryogenesis frequency and the number of embryos generated per cotyledon.

Emergence and survival of somatic embryos postcryopreservation. Data on the effect of low temperature storage time on emergence somatic embryos from alginate beads and survival of

TABLE 1. Secondary somatic embryogenesis of five cocoa genotypes

\begin{tabular}{lcc}
\hline Genotypes & $\begin{array}{c}\text { Embryogenesis } \\
\text { frequency }(\%)\end{array}$ & $\begin{array}{c}\text { Mean no. ofembryos } \\
\text { per cotyledon }( \pm \text { se })\end{array}$ \\
\hline AMAZ 3-2 & 61.65 & $3.85 \pm 3.08$ \\
AMAZ 10-1 & 70.85 & $5.92 \pm 4.21$ \\
AMAZ 12 & 85.00 & $7.43 \pm 2.01$ \\
IMC 14 & 57.50 & $4.99 \pm 4.82$ \\
SIAL 93 & 81.65 & $6.43 \pm 3.10$ \\
\hline
\end{tabular}

Data were collected eight weeks after culture initiation $(n=60)$. $\mathrm{LSD}=4.579$ is the significant difference between two means in a column at $5 \%$ probability. $n=30$ 
somatic embryos of cocoa post-cryopreservation are presented below (Table 2 and Fig. 1).

Regeneration of plantlets. Genotypes regeneration with respect to treatment is presented in individual columns. The regeneration of cocoa genotypes into plantlets responded differently to low temperature storage treatment, but low temperature storage time seems not to have an effect on regeneration into plantlets among individual genotypes.

\section{DISCUSSION}

Induction of secondary somatic embryos. The responses of the five genotypes tested for secondary embryogenesis were variable in terms of frequency of embryo-producing staminodes, ranging from 57.50 to $85.0 \%$ for IMC14 and AMAZ 12, respectively. The number of embryos per cotyledonary explant ranged from 3.85 to $7.43 \%$ for AMAZ 3-2 and AMAZ 12, respectively (Table 1). The somatic embryos generated by the five

TABLE 2. Emergence times of somatic embryos from alginate beads post-cryopreservation in weeks

\begin{tabular}{lccccc}
\hline Treatment & AMAZ 3-2 & AMAZ 10-1 & AMAZ 12 & IMC 14 & SIAL 93 \\
\hline Non frozen & 3 & 4 & 3 & 4 & 4 \\
1 h LN & 10 & 8 & 4 & 12 & 5 \\
4 weeks LN & 10 & 8 & 5 & 12 & 5 \\
8 weeks LN & 10 & 7 & 4 & 12 & 5 \\
\hline
\end{tabular}

Values represent mean time of emergence of somatic embryos from alginate beads. The cocoa genotypes responded differently in terms of the time taken to emerged from the alginate beads.

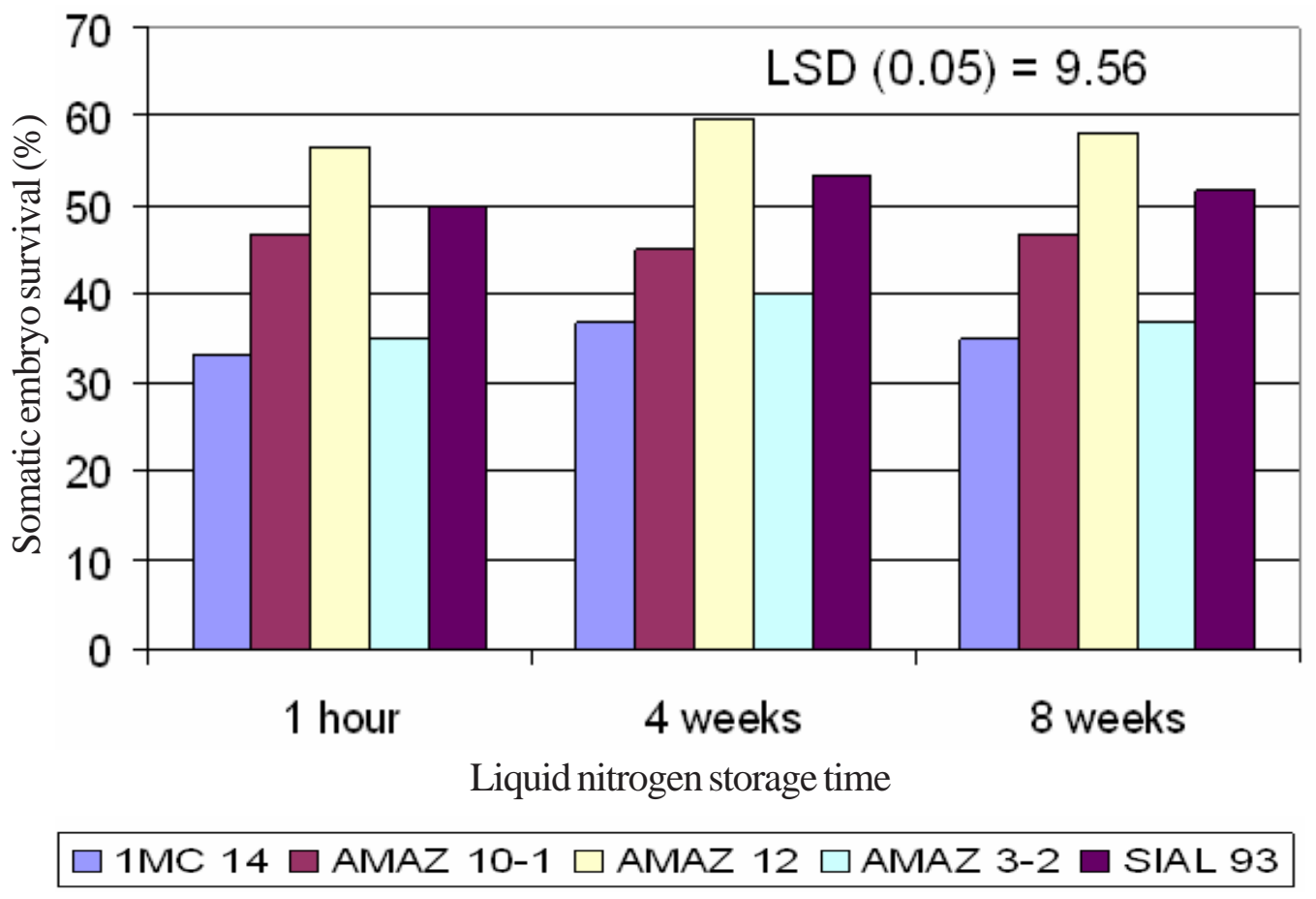

Figure 1. Effect of LN storage time on post-cryopreservation survival of somatic embryos. Values represent mean survival. 
genotypes (at least 500 embryos per genotype over 35 weeks) were sufficient for the experiment. These five genotypes were selected on the basis of flower availability.

Secondary somatic embryogenesis is a phenomenon whereby new somatic embryos are initiated from primary somatic embryos. According to Maximova et al. (2002), primary and secondary somatic embryogenesis of cocoa result from two distinct ontogenetic pathways. Primary somatic embryos are multicellular in origin and unsynchronised, while secondary somatic embryos derived from cotyledons of primary somatic embryos, are unicellular in origins and synchronised. Unicellular somatic embryos have the potential for clonal propagation of cocoa for breeding programmes and the development of genetic transformation (Maximova et al., 2002). The use of secondary somatic embryos for the establishment of cryopreserved collections of cocoa might also reduce the risk of somaclonal variation (Rodriguez Lopez and Wetten, 2004).

Pre-culture and somatic embryo survival. To evaluate the effect of cryopreservation on emergence and survival of somatic embryos from alginate beads, five distinct cocoa genotypes were used (Table 2). Genotypes AMAZ 3-2, AMAZ 10-1 and AMAZ 12 originated from River Amazon, Iquitos Island, Peru but are not parentally related. The non-frozen encapsulated somatic embryos of the genotypes did not show significant $(\mathrm{P}<0.05)$ difference in survival rates as emergence from alginate beads occurred within four weeks post-cryopreservation. There were significant difference in genotypes AMAZ 12, SIAL 93, AMAZ 10-1, AMAZ 3-2 and IMC 14 as the mean emergency time of somatic embryos from alginate beads post-cryopreservation was 4, 5, 8, 10 and 12 weeks, respectively (Table 2). Assuming that the alginate beads used were uniform in size and consistent, the result seem to indicate genotypic differences in the emergence of somatic embryos from the alginate beads.

Individual genotypes subjected to low temperature storage time did not show significant difference in survival, although cryopreservation always reduced overall viability compared to nonfrozen controls (Fabre and Dereuddre, 1990; Hirai and Sakai, 1999). This implies that the trueness of cocoa somatic embryos in terms of survival can be maintained no matter the length of stoarage time in LN. However, different genotypes responded differently to storage time in $\mathrm{LN}$, with genotypes AMAZ 12 and IMC 14 recording the highest and lowest mean somatic embryo survival rates of 58 and 35\%, respectively (Fig. 1).

The low survival of the somatic embryos following cryopreservation may be attributed to the desiccation process, sub-lethal injuries and stress associated with LN exposure of somatic embryos (Fang, 2004). Although, this trial demonstrates differences in survival rates of genotypes stored at low temperature, the postcryopreservation survival range of 35 to $58 \%$ is encouraging and can be applied to other genotypes for future long-term storage of cocoa somatic embryos. Furthermore, survival of the genotypes after rewarming was consistent across all LN storage time (Fig. 1). This implies that storage time in LN did not change the survival pattern of the genotypes, which is significant for long-term storage and conservation of cocoa. The results of this investigation suggest that attempts to improve upon post-cryopreservation survival of somatic embryos should be directed at improving the protocol.

Regeneration of plantlets. Somatic embryogenesis is the most efficient clonal propagation system for cocoa, yet it has been associated with problems of low conversion of somatic embryos into plantlets. The ability of somatic embryos to convert into plantlets is dependent on several factors such as embryo maturation, the synthesis and accumulation of storage compounds and the development of desiccation tolerance (Xu et al., 1990; Blackman et al., 1992).

The high regeneration of somatic embryos post-cryopreservation into plantlets (60 - $71 \%$ ) suggests that LN storage time did not affect the regeneration of the genotypes (Table 3). Fig. 2 represents different stages of the encapsulation and regeneration procedure of somatic embryos.

\section{CONCLUSION}

Low temperature storage time does not affect the survival of the somatic embryos, although 
TABLE 3. Percentage regeneration of somatic embryos post-cryopreservation into plantlets

\begin{tabular}{lccccc}
\hline Treatment & AMAZ 3-2 & AMAZ 10-1 & AMAZ 12 & IMC 14 & SIAL 93 \\
\hline 1 h LN & $10(70)$ & $14(64)$ & $17(65)$ & $10(60)$ & $16(69)$ \\
4 weeks LN & $11(64)$ & $14(64)$ & $18(64)$ & $10(70)$ & $16(63)$ \\
8 weeks LN & $11(64)$ & $14(71)$ & $18(61)$ & $10(60)$ & $16(69)$ \\
\hline
\end{tabular}

Values in brackets ar percentages

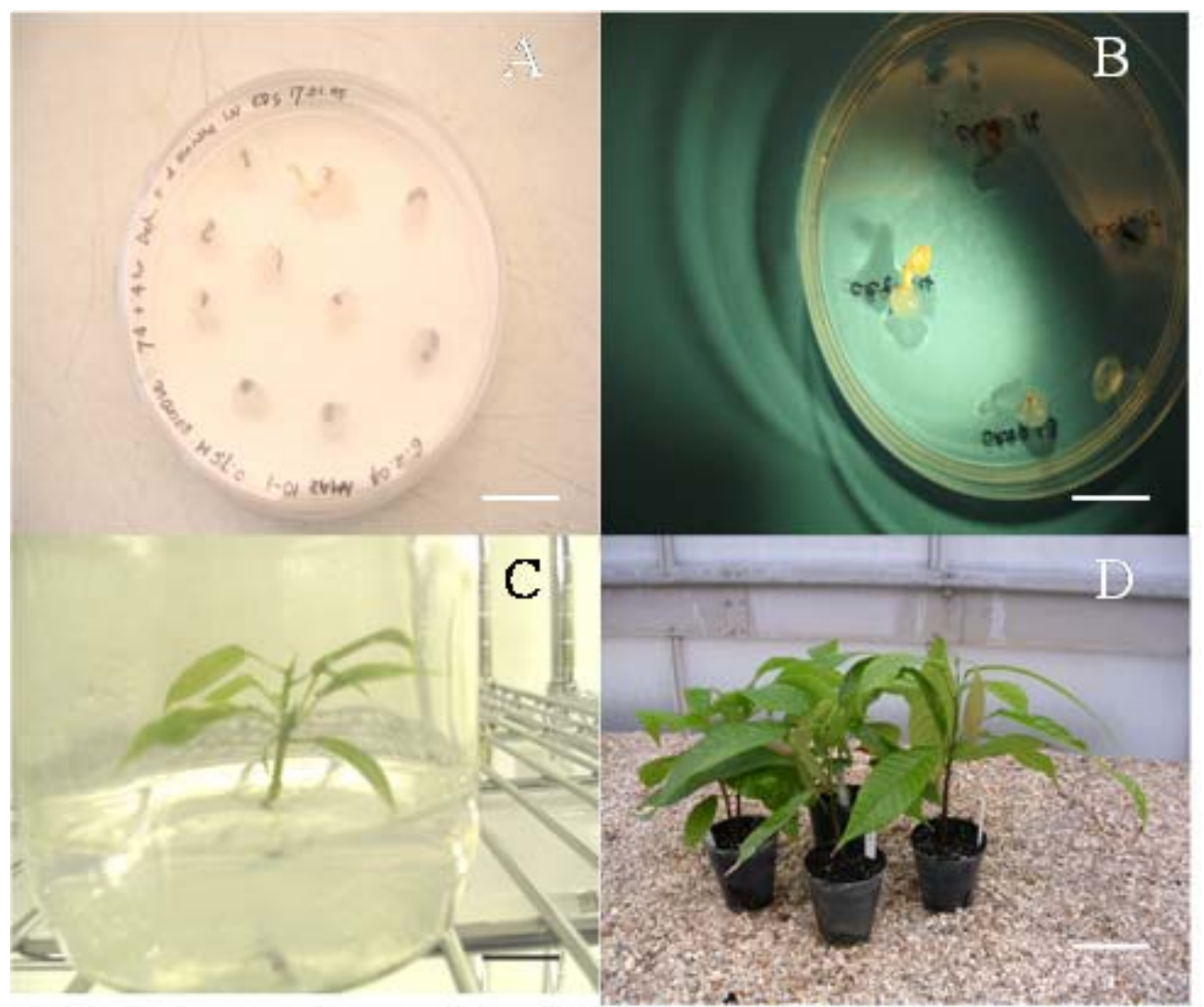

Figure 2. Encapsulated somatic embryos at different stages of development. (A) Encapsulated somatic embryos on ED medium; (B) Alginate bead with an emerging somatic embryo; (C) Encapsulated somatic embryo derived plantlet cultured on primary embryo conversion medium with normal multiple leaves on root induction medium; (D) Plantlets from encapsulated somatic embryos weaned in the glasshouse. (Scale bars: $A$ and $B=2 \mathrm{~mm} ; C$ and $D=1 \mathrm{~cm}$ ).

differences between genotypes were exhibited. The somatic embryos regenerated into plantlets do not show physiological or abnormal characteristics. A better understanding of the effect of LN storage time on the survival and genetic stability of somatic embryos using genotypes from the same parental lines and distinct lines may further contribute to cocoa germplasm materials.

\section{ACKNOWLEDGEMENTS}

This work was supported by a scholarship from the Ghana Government. A. K. Quainoo thanks Dr 
Andy Wetten for supervising his $\mathrm{PhD}$ research and Professor Paul Hadley for the use of facilities at the University of Reading Cocoa Intermediate Quarantine Unit.

\section{REFERENCES}

Benson, E. E. 1999. Cryopreservation. In: Plant Conservation Biotechnology (Ed, Benson, E. E.) T. J. International Ltd, Padstow, pp. 83-95.

Blackman, S. A., Obendorf, R. K. and Leopold, A. C. 1992. Maturation proteins and sugars in desiccation tolerance of developing soybean seeds. Plant Physiology 100: 225-230.

Chandel, K. P. L., Chaudhury, R., Radhmani, J. and Malik, S. K. 1995. Desiccation and freezing sensitivity in recalcitrant seeds of tea, cocoa and jackfruit. Annals of Botany 76: 443450.

Chin, H. F. and Pritchard, H. W. 1988. Recalcitrant seeds, a status report. International Board for Plant Genetic Resources, Rome, Italy.

Engelmann, F. 1991. In vitro conservation of tropical plant germplasm-a review. Euphytica, 57: 227-243.

Fabre, J. and Dereuddre, J. 1990. Encapsulationdehydration: A new approach to cryopreservation of Solanum shoot tips. CryoLetters 11: 413-426.

Fang, J. Y., Wetten, A. and Hadley, P. 2004. Cryopreservation of cocoa (Theobroma cacao L.) somatic embryos for long-term germplasm storage. Plant Science 166: 669675.

Fang. J. Y. 2004. Cryopreservation of somatic embryos for long term germplasm conservation of cocoa (Theobroma cacao L.). Ph.D Thesis. School of Plant Sciences, University of Reading, UK: 215

Florin, B., Brulard, E. and Péfiard, V. 2002. In vitro cryopreservation of cacao genetic resources. In: Cryopreservation of Tropical Plant Germplasm. Engelmann, F. and Takagi, H. (Eds.). Volume 344-347. International Plant Genetic Resourses Institute, Rome, Italy.

Golmirzaie, A. M., Panta, A. and Toledo, J. 1999. Biotechnological advances in the conservation of root and tuber crops. In: Plant Conservation Biotechnology (Ed, Benson, E.
E.) Taylor and Frances, London, UK. pp. 165178.

Hao, Y. I. and Deng, X. X. 2002. Occurrence of chromosomal variations and plant regeneration from long-term-cultured citrus callus. In vitro Cellular and Developmental Biology-Plant 38: 472-476.

Hargreaves, C. L., Smith, D. R. and Fogg, M. N. G., M. E. 1997. Conservation and recovery of Cheeze-mania Chalk Rang an endangered New Zealand Brassicaceous plant. Combined International Plant Propagation Society 47: 132-136.

Hatanaka, T., Yasuda, T., Yamaguchi, T. and Sakai, A. 1994. Direct regrowth of encapsulated somatic embryos of coffee (Coffea canephora) after cooling in liquid nitrogen. Cryo letters 15: 47-52.

Helliot, B., Swennen, R., Poumay, Y. and Frison, E. 2003. Ultrastructural cahnges associated with cryopreservation of banana (Musa spp.) highly proliferating meristems. Plant Cell Report 21:690-698.

Hirai, D. and Sakai, A. 1999. Cryopreservation of in vitro-grown axillary shoot-tip meristems of mint (Mentha spicata L.) by encapsulation vitrification. Plant Cell Report 19: 150-155

Li, Z., Traore, A., Maximova, S. and Guiltinan, M. 1998. Somatic embryogenesis and plant regeneration from floral explants of cacao (Theobroma cacao L.) using thidiazuron. In vitro Cellulara and Developmental BiologyPlants 34: 293-299.

Lynch, P. T. 1999. Application of cryopreservation to the long-term storage of dedifferentiated plant cultures. In: Application of in vitro Plant Germplasm Conservation, Vol. 2 (Ed, Eds, R., M. K. and Cocking, E. C. Oxford Press, Oxford.

Maximova, S. N., Alemanno, L., Young, A., Feffiere, N., Traore, A. and Guiltinan, M. J. 2002. Efficiency, genotypic variability, and cellular origin of primary and secondary somatic embryogenesis of Theobroma cacao L. In vitro Cellular and Developmental Biology-Plant, 38: 252-259.

Pence, V. C. 1991. Cryopreservation of immature embryos of Theobroma cacao. Plant Cell Reports 10: 144-147. 
Rodriguez Lopez, C. M. and Wetten, A. C. 2004. Detection and quantification of in vitroculture induced chimerism using simple sequence repeat (SSR) analysis in Theobroma cacao (L.). Theoretical Applied Geetics 110: 157-166.

Sakai, A. 2004. Plant cryopreservation. In: Life in the Frozen State (Eds, Fuller, B. J., Lane, N. and Benson, E. E.) CRC Press, London, UK. pp. 329-345.

Towill, L. E. 2005. Plant Development and Biotechnology. In: Germplasm Preservation.
Trigiano, R. N. and Gray, D. J. (Eds.). CRC Press. pp. 277-284.

Xu, N., Coulter, K. M. and Bewley, J. D. 1990. Abscisic acid and osmoticum prevent germination of developing alfalfa embryos but only osmoticum maintains the synthesis of developmental proteins. Planta 182: 182-390. Young, A., Miller, C., Antunez de Mayolo, G., Swanson, J. D., Pishak, S., S.N. Maximova, S. N. and Guiltinan, M. J. 2000. Cocoa Tissue Culture Protocol Book, Department of Horticulture, The Pennsylvania State University, USA. 